\title{
Redshift of Excitation Wavelength Caused by the Concentration of L-Tryptophan in Water: A Theoretical and Experimental Study
}

\author{
Diana Milena Uriza-Prias, Antonio Méndez-Blas, Juan Francisco Rivas-Silva* \\ Instituto de Física "Luis Rivera Terrazas", Benemérita Universidad Autónoma de Puebla, Puebla, México \\ Email: ^rivas@ifuap.buap.mx
}

How to cite this paper: Uriza-Prias, D.M., Méndez-Blas, A. and Rivas-Silva, J.F. (2021) Redshift of Excitation Wavelength Caused by the Concentration of L-Tryptophan in Water: A Theoretical and Experimental Study. Open Journal of Physical Chemistry, 11, 87-105.

https://doi.org/10.4236/ojpc.2021.112005

Received: April 21, 2021

Accepted: May 23, 2021

Published: May 26, 2021

Copyright $\odot 2021$ by author(s) and Scientific Research Publishing Inc. This work is licensed under the Creative Commons Attribution International License (CC BY 4.0).

http://creativecommons.org/licenses/by/4.0/

(c) (i) Open Access

\begin{abstract}
A redshift in the wavelength of excitation spectra is experimentally measured as a function of the concentration parameter for tryptophan solutions in water. To understand the microscopic causes of this behavior, theoretical calculations obtained from four model clusters are carried out: $(\operatorname{Trp})_{1}-\left(\mathrm{H}_{2} \mathrm{O}\right)_{9}$, $(\operatorname{Trp})_{2}-\left(\mathrm{H}_{2} \mathrm{O}\right)_{18},(\operatorname{Trp})_{3}-\left(\mathrm{H}_{2} \mathrm{O}\right)_{27}$ and $(\operatorname{Trp})_{4}-\left(\mathrm{H}_{2} \mathrm{O}\right)_{36}$, where there are interactions among 1, 2, 3 and 4 molecules of tryptophan. According to the literature, each interaction occurred with nine molecules of water to stabilize its expected zwitterionic form. In these models, the molecules of tryptophan appear at an adjacent distance among them to generate an analogous behavior when there is an experimental increase in the concentration. It is evident that the distance between adjacent molecules of tryptophan decreases as their concentration increases. The optical properties of these clusters are obtained by studying the corresponding excited states and the molecular orbitals involved, showing charge transfers by using time-dependent density functional theory (TD-DFT) methods. The experimental spectroscopic data are obtained by using the clusters proposed, and good agreement is found by drawing a comparison with the theoretical data.
\end{abstract}

\section{Keywords}

Excitation Spectra, Tryptophan Concentration, Polar Solvent, Molecular Clusters, Time-Dependent Density Functional Theory (TD-DFT) Methods, Electronic Transitions, Fluorescence

\section{Introduction}

L-tryptophan (Trp) is a widely studied amino acid due to its significant intrinsic 
fluorescent properties. The indole groups of tryptophan residues are the dominant source of UV absorbance and emission in proteins [1] [2]. Since a protein may have one or a few tryptophan residues, an analysis of the luminescent and spectral properties of this aromatic amino acid permits to study the functionality and dynamics of proteins [3] [4].

The individual behavior of $\operatorname{Trp}$ as the main source of fluorescence may give some insight into the chemical and biological processes of proteins. One of the essential fluorescent properties of Trp is related to its high sensitivity to the local environment in both polar and non-polar media [5]. The absorption and emission spectra may vary due to the local environment where tryptophan is immersed, changing in response to conformational transitions. Other causes may be the association of subunits, subtraction of bonds, or denaturation [4]. Actually, any interaction that occurs affects fluorescence; for example, the hydrogen bonding formed between a solute and a solvent is very important to understand the physical and chemical processes involved in fluorescence. In recent years, theoretical studies on Trp have focused on the stability of Trp isomers in its neutral structures inside the gas phase and on its zwitterionic structures in aqueous solutions and crystals [6]-[13].

Several theoretical and experimental reports regarding the study of tryptophan in water are related to the chemical and biological processes that allow hydrogen transfer reactions to occur, where its zwitterionic form is attained [12] [14] and which is known to be the most stable geometrical configuration adopted in polar solvents. The number of molecules of water around Trp (its coordination sphere) is essential to stabilize the zwitterion. This zwitterionic structure is studied by modeling the effect of water as a solvent and using continuous or discrete models or a combination of both [14] [15]. In this report, a discrete model was selected by using IR spectroscopy and DFT calculations of tryptophan structures in their zwitterionic form within clusters of Trp- $\left(\mathrm{H}_{2} \mathrm{O}\right)_{n}$ with $n \geq 5$ [12]. For $\beta$-Alanine, Ghassemizadeh et al. [16] show a direct transfer of protons from the amino group to the carboxyl group with five and six molecules of water, which change the Trp molecule from a neutral to a zwitterionic form, thereby leading to two bonds that give rise to the $\mathrm{COO}^{-}$and $\mathrm{NH}_{3}^{+}$ components. These molecules of water form as many hydrogen bonds as possible between them and the zwitterion, so that an additional hydrogen-bonded wire is formed between the charged poles with seven and eight molecules of water. The indole group also needs to consider hydrogen bonds formed in places near the five and six carbon rings. Therefore, nine molecules of water around the tryptophan zwitterion are enough to obtain a complete model, as shown by Liu et al. [13].

Because Trp is a highly flexible molecule with several conformers, other authors have studied some of them in its neutral (in gas phase) and its zwitterionic structure (in polar solvents) [11] [17].

Regarding its neutral form (non-zwitterionic), in 2005, Huang et al. [18] per- 
formed an extensive temperature analysis of $648 \mathrm{Trp}$ proof structures. These authors found 45 conformers representing a local minimum at varying temperatures $(85-498 \mathrm{~K})$. The results are comparable with those obtained by Compagnon et al. (2001) for an isomer at $85 \mathrm{~K}$ [19]. These works showed that their Trp Conformer 1 is a global minimum at DFT and MP2 levels. This conformer is stabilized by a hydrogen bond $\left(\mathrm{COO}-\mathrm{NH}_{3}\right)$ and a favorable interaction between the $\mathrm{COO}-\mathrm{NH}_{2}$ group and the indole group. The authors showed that the dominant conformer is Conformer 1 inside the gas phase with a concentration of more than $99 \%$ at $85 \mathrm{~K}$. At room temperature, its concentration decreases to approximately $50 \%$, so it becomes the fifth lowest energy conformer among the main isomers in the system, thus representing around $80 \%$ of the distribution.

The most stable structure in the gaseous state is different from that in an aqueous environment; thus, its form is expected to change from a neutral to a zwitterionic form. Other conformational analyses of Trp in solution carried out with nuclear magnetic resonance (NMR), molecular dynamics (MD) and DFT calculations have been reported to find the most stable isomer in aqueous media [11] [20] [21] [22]. Hurtado et al. [11] performed a study of the thermodynamic properties of the sixth most stable zwitterionic conformers. Based on this work, the geometry of the most stable structure of their various cases is analyzed in this study.

The electronic transitions that characterize the absorption spectrum of $\operatorname{Trp}$ are often called $L_{a}$ and $L_{b}$ [1] [23] [24] [25] [26] [27], where the $L_{b}$ excited state has an energy and a dipole moment less than the excited state in the gas phase. Furthermore, the $L_{a}$ transition is very sensitive to the environment, especially inside a polar solvent, changing its excitation dipole moment significantly [28] [29] [30]. Similarly, the emission also depends on the solvent, although the participation of the $L_{b}$ state occurs at a lesser extent [4].

Some investigations have claimed that large redshifts appear in Trp fluorescence arising from solvent polarity. Gryczynski et al. [5] experimentally detected a redshift in the emission spectra of Trp in solutions of cyclohexane and ethanol at different concentrations. However, in their absorption spectrum, no evident changes were found. On the other hand, neither theoretical nor experimental evidence of such an effect has been reported when varying the concentration of Trp in solution. Since water is an essential biological solvent, a molecular study of the intermolecular interactions involving excited states may offer some insight into this process.

In this work, a redshift is experimentally observed in the excitation wavelength proportional to the systematic increase in the Trp concentration parameter in water. To understand this effect theoretically, it is necessary to emulate the concentration in a convenient way. A suitable start is the model proposed by Liu et al. [13] that consists of a system of nine molecules of water and one molecule of Trp to stabilize de zwitterionic form. Of course, the zwitterionic form of Trp can also be stabilized at very high concentrations, due to interaction with nearby 
Trp molecules, but this case is not of interest for this work, since it can generate a concentration quenching effect in the fluorescence and this phenomenon deserves another study. Using this structure as a basic entity, the clusters are extended from one to four molecules of Trp, i.e., from $(\operatorname{Trp})_{1}-\left(\mathrm{H}_{2} \mathrm{O}\right)_{9}$ to $(\operatorname{Trp})_{4}-\left(\mathrm{H}_{2} \mathrm{O}\right)_{36}$, maintaining a 1:9 ratio to ensure the stability of the zwitterionic Trp. For the theoretical study, the four clusters present excited states that contain the effects of an ever-increasing interaction among Trps that allows the distance between them to decrease within the clusters.

\section{Experimental Details}

L-Tryptophan with a purity of $\geq 99.5 \%$ was purchased at Sigma-Aldrich. Nine solutions were prepared, dissolving Trp in deionized water obtaining concentrations of $0.01,0.02,0.05,0.07,0.09,0.5,1,2$ and $5 \mathrm{mM}$. Then, the absorption spectrum was measured with a UV-Vis-NIR spectrophotometer model Agilent Cary 5000. Additionally, the excitation and emission spectra were obtained with a Horiba Jobin-Yvon spectrofluorometer model Nanolog.

\section{Computational Details}

According to the literature, it is important to mention that there are different Trp conformers to carry out the calculations of this study [6] [7] [9] [13] [18], from which the most convenient conformers must be selected to perform this work. They are characterized by the dihedral angles $\chi^{1}\left(\mathrm{C}_{3}-\mathrm{C}_{\beta}-\mathrm{C}_{\alpha}-\mathrm{N}\right)$ with values at approximately $180^{\circ}, 60^{\circ}$ and $-60^{\circ}$, commonly labeled as $g^{+}, t$ and $g$ due to their gauche and trans bonds, and $\chi^{2}\left(\mathrm{C}_{\alpha}-\mathrm{C}_{\beta}-\mathrm{C}_{3}-\mathrm{C}_{3}\right)$ with values at approximately $90^{\circ}$ and $-90^{\circ}$, commonly labeled as $p$ (perpendicular) and $a$ (anti-perpendicular), respectively (Figure 1) Dezube et al. [20] and Eriksen et al. [21] performed a conformational analysis of Trp in solution by using molecular dynamics at $300 \mathrm{~K}$ and molecular mechanics simulations. They demonstrated that the predominant conformation occurs where the ring has a perpendicular orientation $\mathrm{p}$ and a bond in configuration $g$, as observed by NMR [31].

By modeling with a discrete solvent method, (Trp + explicit molecules of water), corresponding to important solute-solvent interactions are taken into account within the system. Thus, the conformer having a $t$ type bond and a perpendicular orientation $p$, labeled as $Z p t$, is the most stable conformer. Hurtado et al. [11] confirmed this stability by analyzing the six most stable zwitterionic conformers reported by Huang et al. [18], surrounding them with eight molecules of water. However, it is experimentally possible to have a combination of different conformers that individually contribute to the total fluorescence. Therefore, the $\mathrm{Zag}^{+}$conformer was considered to represent the zwitterionic conformer of the neutral $\mathrm{Nag}^{+}$structure, since different authors have reported that it corresponds to the minimum energy in the gas phase [6] [7] [8] [9]. As mentioned above, a discrete model with nine molecules of water are used.

In the calculation process, the conformers $\mathrm{Zpt}$ and $\mathrm{Zag}^{+}$were used as starting 


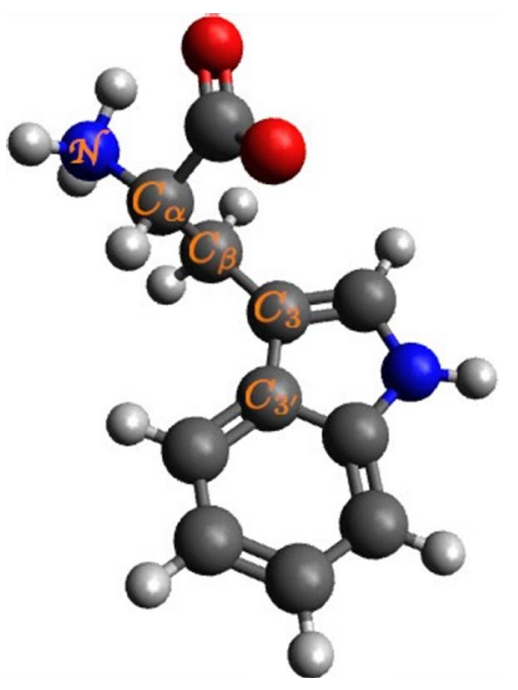

Figure 1. Dihedral angles of the Trp structure, as proposed by Huang et al. [18]. The angles $\chi^{1}$ and $\chi^{2}$ are defined as $\left(\mathrm{C}_{3}-\mathrm{C}_{\beta}-\mathrm{C}_{\alpha}-\mathrm{N}\right)$ and $\left(\mathrm{C}_{\alpha}-\mathrm{C}_{\beta}-\mathrm{C}_{3}-\mathrm{C}_{3}\right)$, respectively.

structures, since Hurtado et al. [11] have previously demonstrated that these structures are local minima.

Since studying the optical properties of a system, such as the absorption and emission of light, requires a quantum mechanics treatment, the methodology of time-dependent density functional theory (TD-DFT) was selected to perform this work. The algorithm accepted first involves obtaining the optimized ground state of the system and, then, the vertical transitions between electronic states, accepting the Born-Oppenheimer approximation. Once the model of $\operatorname{Trp}+9$ molecules of water was selected to carry out this work, the first problem was to find the nuclear positions of atoms in the ground state. To solve this problem, the interactions on each part of the system must be correctly considered; thus, the molecule of Trp must have enough molecules of water to reach its zwitterionic form and the surrounding molecules of water must have accurate interactions.

In the discrete model used in this work, the molecules of water closest to $\operatorname{Trp}$ have a strong interaction among each other and with Trp, while the molecules of water located farther away from Trp stop interacting with it, but they continue interacting among each other because of the imposed standard area of vacuum. Consequently, it is difficult to obtain a correct geometrical optimization of the cluster, especially if a realistic environment is taken into consideration as it is the case for this model. Increasing the number of explicit molecules of water around Trp is impractical, since it is difficult to establish a boundary where the molecules of water do not interact because they are always doing it. Therefore, a molecular mechanics (MM) calculation [32] [33] is carried out to consider hundreds of molecules of water, allowing a more realistic modeling through the periodic boundary conditions.

In the MM calculation procedure [34], atoms are considered as point particles; thus, 200 molecules of water surrounding the molecule of Trp are taken into account inside the cell. Then, Dreiding Force Field parameters [35] are ap- 
plied in the calculation and, after a step from NTV dynamics to $\mathrm{T}=300 \mathrm{~K}$, a system that includes the average of all the possible internal atomic positions is obtained according to its energy. In the last step of the calculation, the coordinates corresponding to the atoms of the $(\operatorname{Trp})_{1}-\left(\mathrm{H}_{2} \mathrm{O}\right)_{9}$ cluster are obtained, from which further information about the precise environment is expected to be available, even if it is immersed in a vacuum. This process generates the initial geometry to perform a quantum mechanics calculation accordingly, which requires as a first step to optimize its geometry at the level of quantum chemistry and, subsequently, to calculate its vertical transitions.

Four clusters were built from the base unit of $(\operatorname{Trp})_{1}-\left(\mathrm{H}_{2} \mathrm{O}\right)_{9}$, with the molecules of Trp and the molecules of water increasing at the same rate in two, three and four units at reduced distances to model the concentration based on their possible interactions. To compare the theoretical results provided by the different clusters, the semi-empirical level PM6 [36] was selected to optimize the geometry of the ground state. Then, to study their optical properties, the TD-DFT method was used since it is an effective tool to calculate the electronic transitions. This method was used after obtaining the geometry of the ground state because it can identify the effects of the formation of hydrogen bonds on the excited molecular state and, therefore, allows the fluorescence of the smaller cluster to be analyzed [37]-[44].

The difference between the geometry of the ground state and the electronically excited state mainly occurs due to Stokes shifts, which are the difference between the emission and absorption energies. Therefore, the hybrid functional B3LYP [45] and the $6-31+\mathrm{G}(\mathrm{d}, \mathrm{p})$ basis sets were selected, which include polarized functions [46] [47]. The fluorescent excited states can only be calculated for the two smaller clusters, since it is necessary to optimize the full geometry of the ground state and the selected excited state to emit at the same B3LYP/6-31+ G(d,p) level [48] [49] [50], and the other two clusters are too large to be optimized at this level. All calculations of quantum chemistry were performed with Gaussian 16 [51].

\section{Results and Discussion}

\subsection{Experimental Results}

Figure 2 shows the overlapping of normalized absorption and excitation spectra of Trp in water for each concentration. In general, the absorption peak is located at $278 \mathrm{~nm}$. It can be observed that both spectra practically overlap within the concentration values from 0.01 to $0.09 \mathrm{mM}$. However, at higher concentrations in the range from 0.5 to $5 \mathrm{mM}$, the absorption and excitation spectra peaks differ from each other. The excitation spectrum shows an apparent displacement at longer wavelengths as the concentration increases from 278 to $303 \mathrm{~nm}$.

Figure 3 displays the emission spectra of Trp in deionized water at concentration solutions from 0.01 to $5 \mathrm{mM}$. At lower concentrations, from 0.01 to 0.09 $\mathrm{mM}$, the curves were obtained by using excitation at $278 \mathrm{~nm}$. On the other hand, 


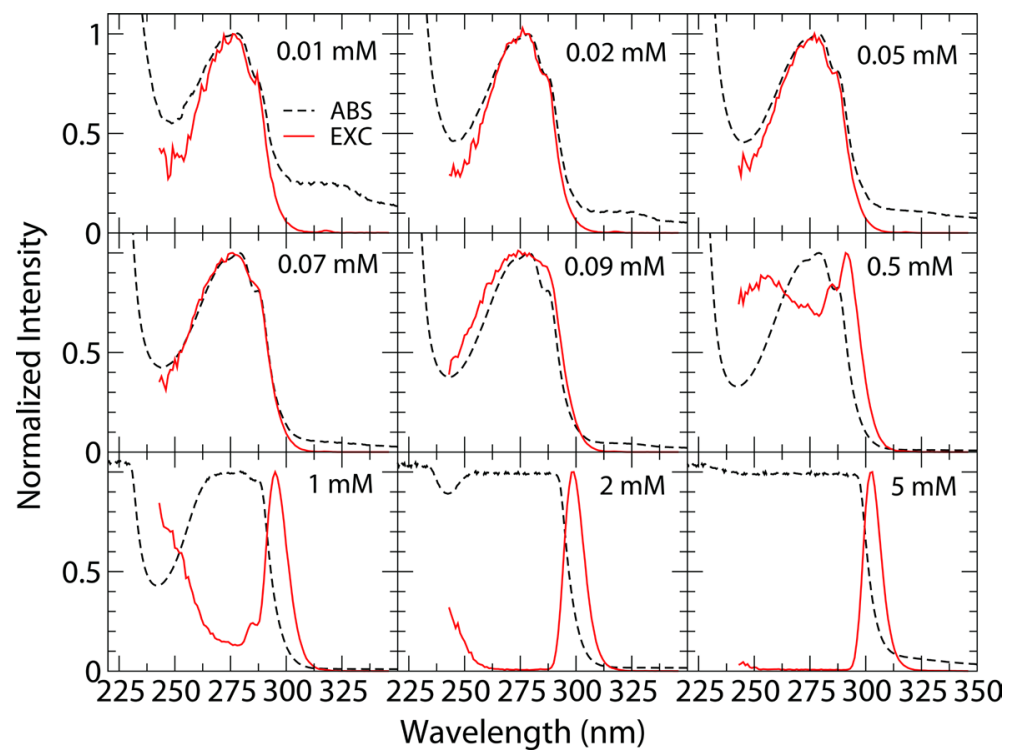

Figure 2. Comparison between normalized absorption (dotted black line) and excitation spectra (red line) for different concentrations of tryptophan in water. In each panel, $\lambda_{e m}=357 \mathrm{~nm}$.

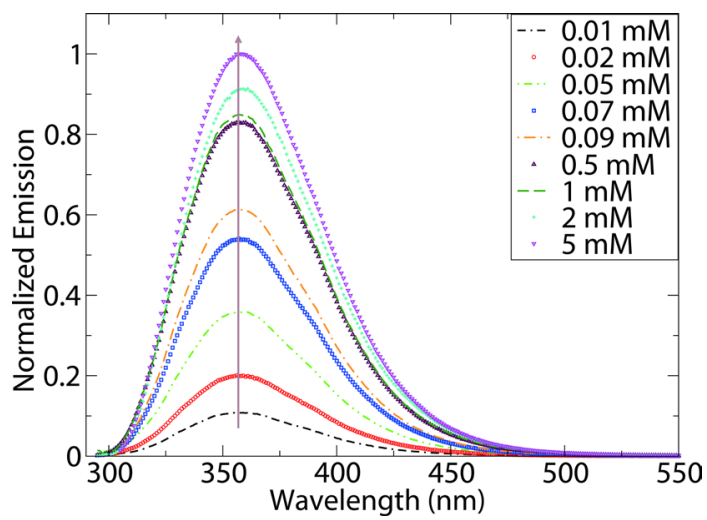

Figure 3. Normalized emission spectra for different concentrations of tryptophan in water.

the emission at higher concentrations was obtained by using excitations at 293 $\mathrm{nm}$ for $0.5 \mathrm{mM}$, at $295 \mathrm{~nm}$ for $1 \mathrm{mM}$, at $299 \mathrm{~nm}$ for $2 \mathrm{mM}$ and at $303 \mathrm{~nm}$ for 5 $\mathrm{mM}$. This emission occurs because there is a redshift in the excitation curves. It can be observed that the intensity of fluorescence increases with concentration without modifying the emission peak wavelength at $357 \mathrm{~nm}$.

\subsection{Theoretical Results}

\subsubsection{Absorption Analysis}

Before presenting the absorption calculations, the concept of high concentration used in this work is further discussed. By definition, the mass concentration is proportional to the ratio of the mass of the solute to the volume of the solution. In this regard, Figure 4 presents the increase in solute concentration in a solvent. At low solute concentrations, the distance between the molecules is very long, but as the concentration increases, the average separation distance decreases allowing 


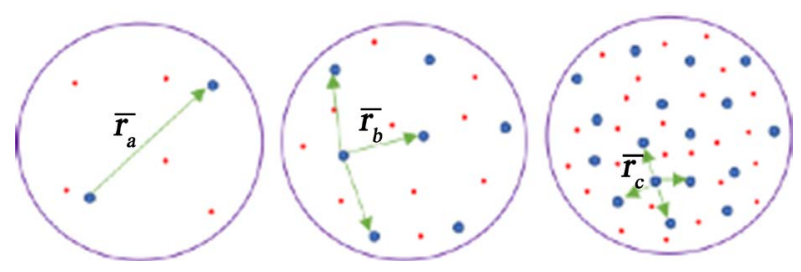

Figure 4. Qualitative illustration of the mass of a solute at a given volume increasing with concentration. At low solute concentrations, the average separation distance between solute molecules is long, but it decreases as the concentration increases, thus $\bar{r}_{a}>\bar{r}_{b}>\overline{r_{c}}$.

the molecules to have a stronger interaction. Then, the main parameter to consider here is the distance between molecules. Due to the absence of a volume parameter in this series of calculations (having a molecular cluster surrounded by an infinite vacuum), it is important to consider the distance between the molecules of Trp. Under this evidence, the clusters were built keeping in mind two purposes: 1) ensuring that each molecule of Trp acquires its correct zwitterionic form, surrounding it with nine molecules of water, and 2) using this first case as a base unit to build larger clusters, looking for a close distance between the molecules of Trp. The result is the obtaining of the $(\operatorname{Trp})_{1}-\left(\mathrm{H}_{2} \mathrm{O}\right)_{9},(\operatorname{Trp})_{2}-\left(\mathrm{H}_{2} \mathrm{O}\right)_{18}$, $(\operatorname{Trp})_{3}-\left(\mathrm{H}_{2} \mathrm{O}\right)_{27}$, and $(\operatorname{Trp})_{4}-\left(\mathrm{H}_{2} \mathrm{O}\right)_{36}$ clusters. The way of modeling these clusters does not depend on the volume parameter, but a simple way of doing it is to take the starting point as $(\operatorname{Trp})_{1}-\left(\mathrm{H}_{2} \mathrm{O}\right)_{36}$, followed by $(\operatorname{Trp})_{2}-\left(\mathrm{H}_{2} \mathrm{O}\right)_{36}$, then $(\operatorname{Trp})_{3}-\left(\mathrm{H}_{2} \mathrm{O}\right)_{36}$, and, finally, $(\operatorname{Trp})_{4}-\left(\mathrm{H}_{2} \mathrm{O}\right)_{36}$, where the number of molecules of Trp increases, while the number of molecules of water remain fixed, but it is still necessary to consider the correct interactions on each surrounding molecule of water and to control the volume parameter.

Using the clusters for the $Z p t$ and $Z_{a g} g^{+}$conformers, the excited electronic states were calculated to obtain the absorption UV-Vis spectra, and the effects of molecular interactions were searched according to concentration values. Figure 5 and Figure 6 show that the envelope of the absorption spectra is in the same region at approximately $278 \mathrm{~nm}$, and its intensity increases as the clusters are larger, as it occurs experimentally. In addition, the lower energy transitions show redshifts when there are more interactions between the molecules of Trp, which is a behavior analogous to the excitation spectra shown in Figure 2. The transition lines for the smallest cluster are observed at approximately $280 \mathrm{~nm}$ using the most stable conformer, which is the Zpt conformer. They occur at approximately $288 \mathrm{~nm}$ with three molecules of $\operatorname{Trp}$ and at approximately $301 \mathrm{~nm}$ for the largest cluster. The redshift of the transition lines occurs at a shorter distance for the $\mathrm{Zag}^{+}$conformer, but now the excited states range from $278 \mathrm{~nm}$ for the smallest cluster to $295 \mathrm{~nm}$ for the largest one.

In electronic spectroscopy, excitation spectra are directly related to emission spectra; thus, excitation spectra only show the absorption bands necessary to promote photonemission, whereas the absorption spectra measure the wavelengths at which a molecule absorbs light, regardless of its emission spectra. Sometimes excitation spectra are the same as absorption spectra, as it can be 


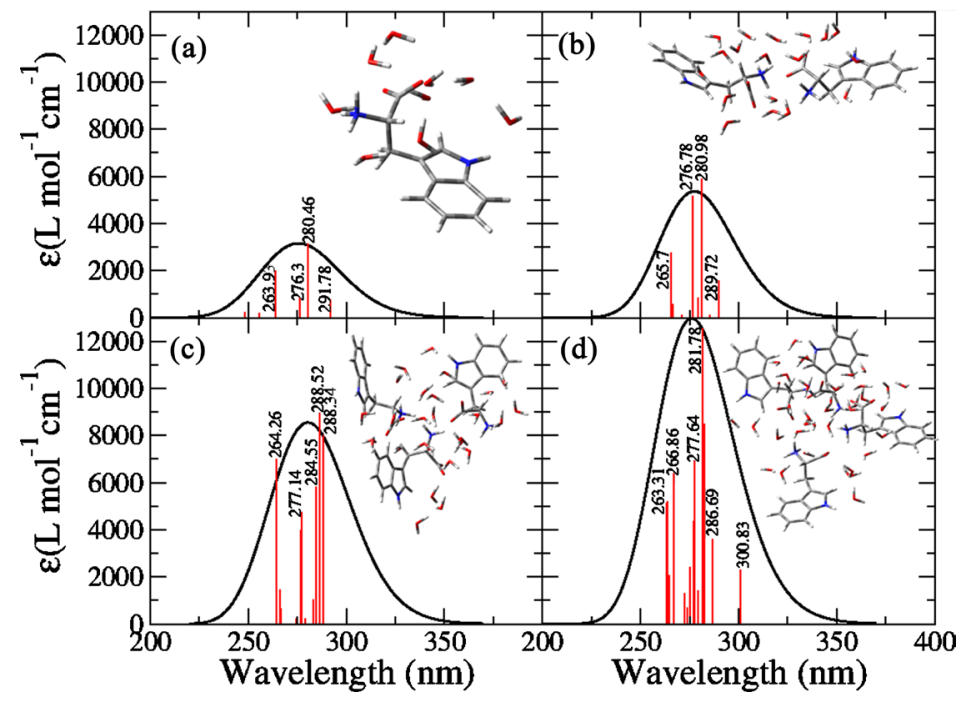

Figure 5. UV-Vis absorption spectra calculated for the $Z p t$ conformer in the modeled clusters. (a) $(\operatorname{Trp})_{1}-\left(\mathrm{H}_{2} \mathrm{O}\right)_{9}$, (b) $(\operatorname{Trp})_{2}-\left(\mathrm{H}_{2} \mathrm{O}\right)_{18}$, (c) $(\operatorname{Trp})_{3}-\left(\mathrm{H}_{2} \mathrm{O}\right)_{27}$ and (d) $(\operatorname{Trp})_{4}$ $\left(\mathrm{H}_{2} \mathrm{O}\right)_{36}$.

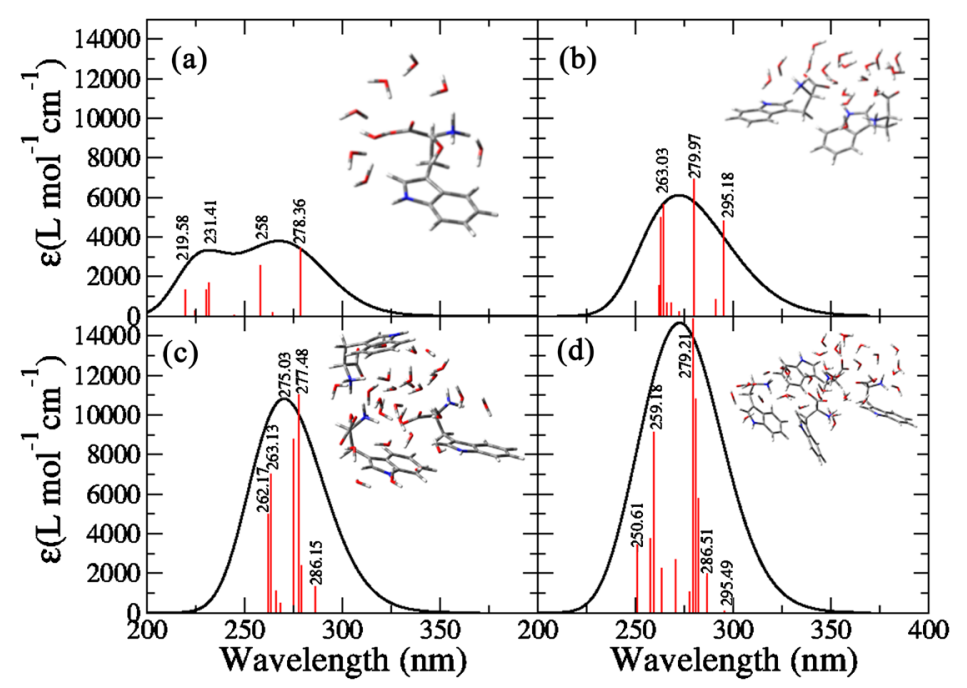

Figure 6. UV-Vis absorption spectra calculated for the $\mathrm{Zag}^{+}$conformer in the modeled clusters. (a) $(\operatorname{Trp})_{1}-\left(\mathrm{H}_{2} \mathrm{O}\right)_{9}$, (b) $(\operatorname{Trp})_{2}-\left(\mathrm{H}_{2} \mathrm{O}\right)_{18}$, (c) $(\operatorname{Trp})_{3}-\left(\mathrm{H}_{2} \mathrm{O}\right)_{27}$ and (d) $(\operatorname{Trp})_{4}$ $\left(\mathrm{H}_{2} \mathrm{O}\right)_{36}$.

observed in Figure 2 for concentrations below $0.07 \mathrm{mM}$, but for concentrations above $0.09 \mathrm{mM}$, both spectra are different due to the fluorescence of the system. In this respect, Figure 7 presents a comparison of some experimental results with the $S_{2}$ and $S_{1}$ excited states of the smallest and largest cluster by using the $Z p t$ conformer, respectively. The wavelengths of these excited states are those that bestapproximates the peaks of the excitation spectra of the lowest and highest concentrations, respectively. The lowest concentration can be observed at $0.01 \mathrm{mM}$, which occurs in a peak at $278 \mathrm{~nm}$ in the excitation spectrum and is similar to the electronic excitation calculated at $280 \mathrm{~nm}$ for the smallest cluster, $(\operatorname{Trp})_{1}-\left(\mathrm{H}_{2} \mathrm{O}\right)_{9}$. The highest concentration at $5 \mathrm{mM}$ results in a peak at $303 \mathrm{~nm}$ 


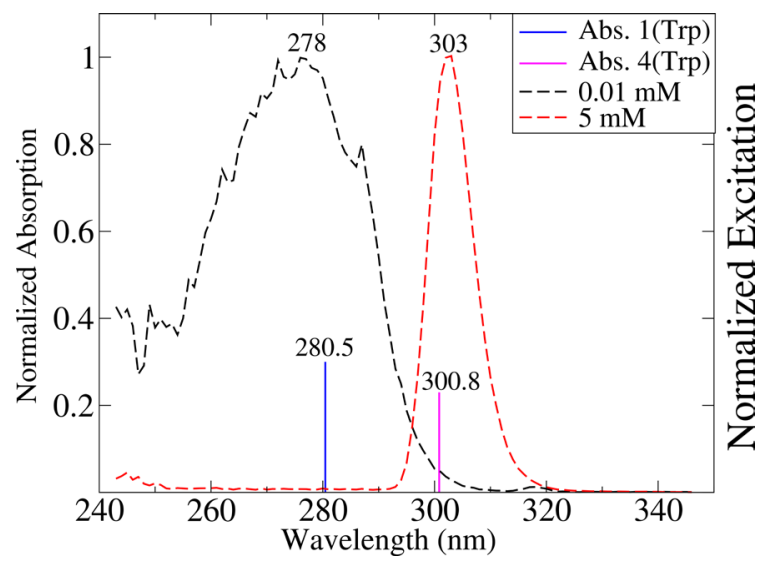

Figure 7. Experimental excitation spectra of the Trp in water for the 0.01 and $5 \mathrm{mM}$ concentrations, represented by the black and red dotted lines, respectively. The electronic excitation states for the $(\operatorname{Trp})_{1}-\left(\mathrm{H}_{2} \mathrm{O}\right)_{9}$ and $(\operatorname{Trp})_{4}-\left(\mathrm{H}_{2} \mathrm{O}\right)_{36}$ are shown in blue and pink lines, respectively.

in the excitation spectrum and is also very close to the electronic excitation spectra calculated at $301 \mathrm{~nm}$ for the largest cluster $(\operatorname{Trp})_{4}-\left(\mathrm{H}_{2} \mathrm{O}\right)_{36}$. Therefore, the modeling proposed by this work is reasonably successful.

\subsubsection{Frontier Molecular Orbitals (MOs)}

Table 1 contains the details of the TD-DFT results, focusing on the $Z p t$ conformer for the low-lying and most representative excited states of the $(\operatorname{Trp})_{1}$ $\left(\mathrm{H}_{2} \mathrm{O}\right)_{9},(\operatorname{Trp})_{2}-\left(\mathrm{H}_{2} \mathrm{O}\right)_{18},(\operatorname{Trp})_{3}-\left(\mathrm{H}_{2} \mathrm{O}\right)_{27}$, and $(\operatorname{Trp})_{4}-\left(\mathrm{H}_{2} \mathrm{O}\right)_{36}$ clusters. The absorption energies are described for the singlet-singlet $\left(S_{0} \rightarrow S_{n}\right)$ transitions obtained for the discrete model. The composition of the excited states based on the molecular orbital contributions occurs as follows: H: HOMO, L: LUMO, H-1: HOMO $-1, \mathrm{~L}+1$ : LUMO +1 , etc. Some molecular orbitals in Table 1 are shown in Figure 8. It should be mentioned that the number of excited states calculated for each cluster increases as the number of molecules of Trp also grows, since each molecule of Trp produces a significant contribution, reflected in the oscillator strength value.

Table 1 presents the excitation states discussed below. For the first $(\operatorname{Tr} p)_{1}$ $\left(\mathrm{H}_{2} \mathrm{O}\right)_{9}$ cluster, the $\mathrm{S}_{2}$ excited state has the greatest oscillator strength parameter $(f)$. It also has a HOMO $\rightarrow$ LUMO $+1(49.36 \%)$ contribution, which presents a $\pi-\sigma^{*}$ character, with the main transition given from the indole group to the side chain and to all the molecules of water. The HOMO $\rightarrow$ LUMO + 2 (28.17\%) transition also appears, although it shows a less contribution to $S_{2}$ and a transition from indole to indole group and to the side chain. It should be pointed out that other authors have studied the molecular orbitals of the indole group and found that the $L_{a}$ transition occurs mainly due to contributions of HOMO to LUMO transitions and small amounts of HOMO -1 to HOMO +1 . Furthermore, the $L_{b}$ transition occurs due to the contribution of HOMO to LUMO+1 and HOMO - 1 to LUMO excitations [1]. In this work, however, the effect of solvent interactions modify the $L_{a}$ and $L_{b}$ transitions, but the $S_{2}$ excited state is 
Table 1. Transition energies $(E)$ in $\mathrm{eV}$ and wavelength $(\lambda)$ in $\mathrm{nm}$, with oscillator strength $(f)$, and the composition of the orbitals that contribute to the transition of the four clusters with $Z p t$ conformer, respectively.

\begin{tabular}{|c|c|c|c|c|c|}
\hline Cluster & State & $\begin{array}{l}\text { One-electron } \\
\text { excitation }\end{array}$ & Composition & $E(\mathrm{eV})(\lambda(\mathrm{nm}))$ & $f$ \\
\hline \multirow[t]{8}{*}{$(\operatorname{Trp})_{1}-\left(\mathrm{H}_{2} \mathrm{O}\right)_{9}$} & $S_{1}$ & $76.57 \%$ & $\mathrm{H} \rightarrow \mathrm{L}$ & 4.25 (291.78) & 0.0098 \\
\hline & & $15.92 \%$ & $\mathrm{H} \rightarrow \mathrm{L}+2$ & & \\
\hline & $S_{2}$ & $49.36 \%$ & $\mathrm{H} \rightarrow \mathrm{L}+1$ & $4.42(280.46)$ & 0.0401 \\
\hline & & $28.17 \%$ & $\mathrm{H} \rightarrow \mathrm{L}+2$ & & \\
\hline & $S_{3}$ & $50.79 \%$ & $\mathrm{H} \rightarrow \mathrm{L}+2$ & $4.49(276.30)$ & 0.0108 \\
\hline & & $42.40 \%$ & $\mathrm{H} \rightarrow \mathrm{L}+1$ & & \\
\hline & $S_{4}$ & $57.89 \%$ & $\mathrm{H}-1 \rightarrow \mathrm{L}$ & $4.70(263.93)$ & 0.0254 \\
\hline & & $27.24 \%$ & $\mathrm{H} \rightarrow \mathrm{L}+6$ & & \\
\hline \multirow[t]{8}{*}{$(\operatorname{Trp})_{2}-\left(\mathrm{H}_{2} \mathrm{O}\right)_{18}$} & $S_{1}$ & $82.11 \%$ & $\mathrm{H}-1 \rightarrow \mathrm{L}+1$ & $4.28(289.72)$ & 0.0129 \\
\hline & & $13.55 \%$ & $\mathrm{H}-1 \rightarrow \mathrm{L}+2$ & & \\
\hline & $S_{3}$ & $89.81 \%$ & $\mathrm{H} \rightarrow \mathrm{L}+2$ & $4.41(280.98)$ & 0.0491 \\
\hline & & $3.43 \%$ & $\mathrm{H}-2 \rightarrow \mathrm{L}+11$ & & \\
\hline & $S_{5}$ & $78.07 \%$ & $\mathrm{H}-1 \rightarrow \mathrm{L}+1$ & $4.48(276.78)$ & 0.0429 \\
\hline & & $11.68 \%$ & $\mathrm{H}-1 \rightarrow \mathrm{L}$ & & \\
\hline & $S_{8}$ & $49.41 \%$ & $\mathrm{H}-3 \rightarrow \mathrm{L}$ & $4.67(265.70)$ & 0.0231 \\
\hline & & $20.70 \%$ & $\mathrm{H}-1 \rightarrow \mathrm{L}+9$ & & \\
\hline \multirow[t]{12}{*}{$(\operatorname{Trp})_{3}-\left(\mathrm{H}_{2} \mathrm{O}\right)_{27}$} & $S_{1}$ & $81.87 \%$ & $\mathrm{H}-2 \rightarrow \mathrm{L}$ & $4.30(288.34)$ & 0.0449 \\
\hline & & $4.53 \%$ & $\mathrm{H}-2 \rightarrow \mathrm{L}+4$ & & \\
\hline & $S_{2}$ & $70.52 \%$ & $\mathrm{H}-1 \rightarrow \mathrm{L}+1$ & $4.33(286.52)$ & 0.0500 \\
\hline & & $19.78 \%$ & $\mathrm{H}-1 \rightarrow \mathrm{L}$ & & \\
\hline & $S_{3}$ & $55.93 \%$ & $\mathrm{H} \rightarrow \mathrm{L}+3$ & $4.36(284.55)$ & 0.0323 \\
\hline & & $19.37 \%$ & $\mathrm{H} \rightarrow \mathrm{L}$ & & \\
\hline & $S_{6}$ & $62.71 \%$ & $\mathrm{H} \rightarrow \mathrm{L}+6$ & $4.47(277.14)$ & 0.0263 \\
\hline & & $14.43 \%$ & $\mathrm{H} \rightarrow \mathrm{L}+3$ & & \\
\hline & $S_{7}$ & $52.06 \%$ & $\mathrm{H}-2 \rightarrow \mathrm{L}+2$ & $4.48(276.70)$ & 0.0239 \\
\hline & & $27.18 \%$ & $\mathrm{H}-2 \rightarrow \mathrm{L}+5$ & & \\
\hline & $S_{15}$ & $40.72 \%$ & $\mathrm{H}-4 \rightarrow \mathrm{L}$ & $4.69(264.26)$ & 0.0391 \\
\hline & & $18.65 \%$ & $\mathrm{H}-2 \rightarrow \mathrm{L}+13$ & & \\
\hline \multirow[t]{6}{*}{$(\operatorname{Trp})_{4}-\left(\mathrm{H}_{2} \mathrm{O}\right)_{36}$} & $S_{1}$ & $64.34 \%$ & $\mathrm{H} \rightarrow \mathrm{L}+3$ & $4.12(300.83)$ & 0.0133 \\
\hline & & $24.66 \%$ & $\mathrm{H} \rightarrow \mathrm{L}+2$ & & \\
\hline & $S_{3}$ & $34.85 \%$ & $\mathrm{H}-1 \rightarrow \mathrm{L}+4$ & $4.32(286.69)$ & 0.0203 \\
\hline & & $24.59 \%$ & $\mathrm{H}-1 \rightarrow \mathrm{L}$ & & \\
\hline & $S_{5}$ & $89.95 \%$ & $\mathrm{H}-3 \rightarrow \mathrm{L}$ & $4.39(282.47)$ & 0.0480 \\
\hline & $S_{6}$ & $82.94 \%$ & $\mathrm{H}-2 \rightarrow \mathrm{L}+1$ & $4.40(281.78)$ & 0.0711 \\
\hline
\end{tabular}




\begin{tabular}{lcccc} 
Continued & \multicolumn{1}{c}{} & & \\
\hline & $6.08 \%$ & $\mathrm{H}-2 \rightarrow \mathrm{L}+2$ & & \\
$S_{9}$ & $86.19 \%$ & $\mathrm{H} \rightarrow \mathrm{L}+5$ & $4.47(277.64)$ & 0.0391 \\
& $15.00 \%$ & $\mathrm{H} \rightarrow \mathrm{L}+1$ & & \\
$S_{10}$ & $29.67 \%$ & $\mathrm{H}-1 \rightarrow \mathrm{L}+1$ & $4.48(276.97)$ & 0.0249 \\
& $18.70 \%$ & $\mathrm{H}-1 \rightarrow \mathrm{L}+8$ & & \\
$S_{16}$ & $46.39 \%$ & $\mathrm{H}-4 \rightarrow \mathrm{L}+3$ & $4.65(266.86)$ & 0.0360 \\
& $19.56 \%$ & $\mathrm{H}-4 \rightarrow \mathrm{L}+2$ & & \\
& $47.40 \%$ & $\mathrm{H}-6 \rightarrow \mathrm{L}+1$ & $4.70(263.73)$ & 0.0296 \\
& $10.77 \%$ & $\mathrm{H}-6 \rightarrow \mathrm{L}+2$ & & \\
\hline
\end{tabular}

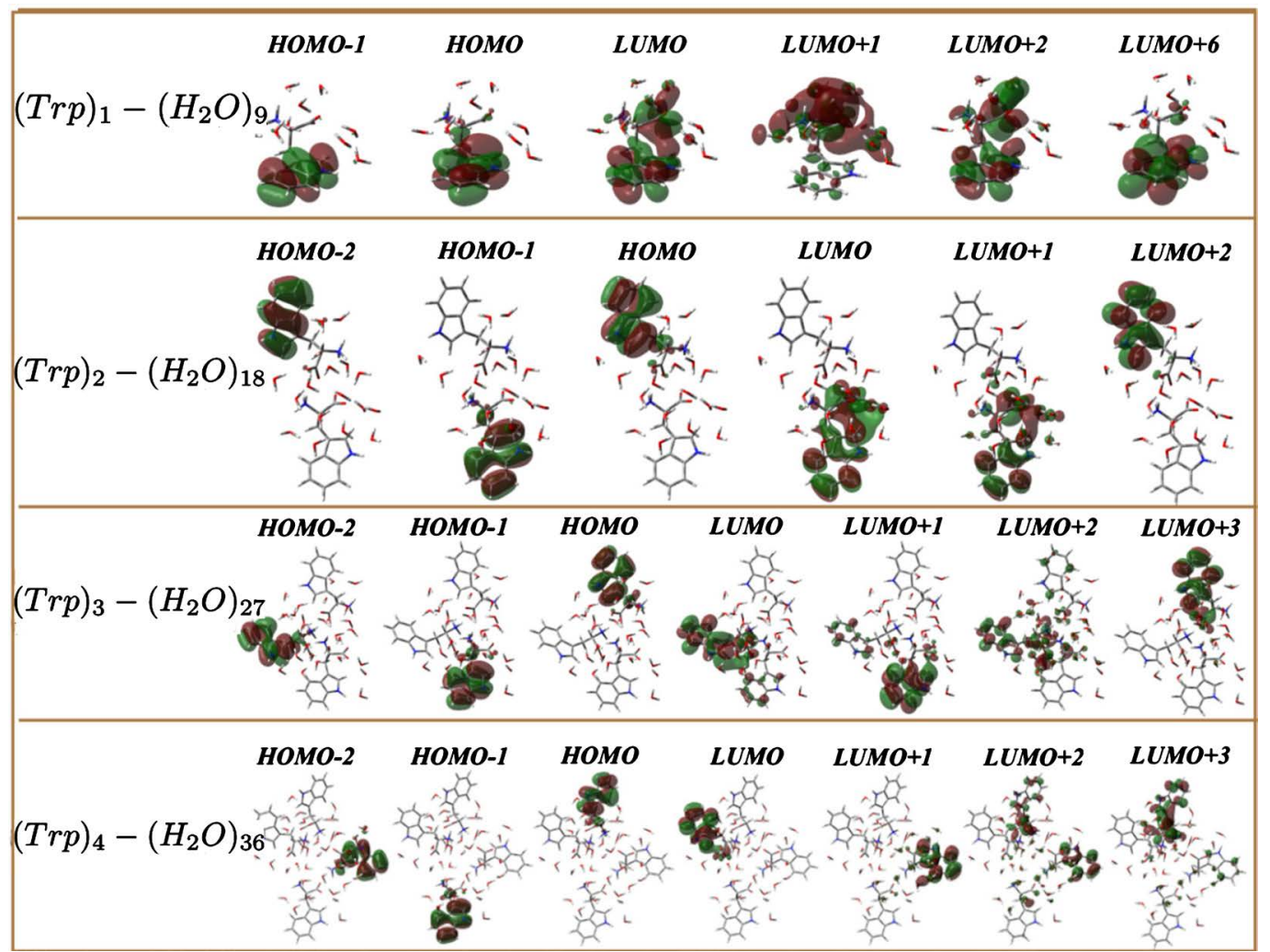

Figure 8. Graphical presentation of the highest representative occupied and the lowest representative unoccupied molecular orbitals involved in the absorption lines of the four clusters obtained by using TD-DFT/B3LYP/6-311 + G(d,p)//PM6 calculations.

labeled as $L_{b}$ and the $S_{4}$ excited state is labeled as $L_{a}$ because of their energies. Nevertheless, the TD-DFT/B3LYP/6-311G + (d,p) method produces mixed transition states, i.e., the $L_{a}$ and $L_{b}$ transitions are not pure. Thus, the $S_{1}$ and $S_{3}$ excited states also contain contributions to the $L_{b}$ and $L_{a}$ transitions, respectively.

For the $(\operatorname{Trp})_{2}-\left(\mathrm{H}_{2} \mathrm{O}\right)_{18}$ cluster, the $S_{3}$ excited state has the largest oscillator strength parameter and the main contribution (89.81\%) of type $\pi \rightarrow \pi^{*}$, where label 1 refers to the first Trp of the cluster, and the transition can be identified as $L_{b 1}$ (Table 1 ). Similarly, the exited state $S_{1}$ has a contribution of $82.11 \%$ of type 
$\pi_{2} \rightarrow \pi_{2}^{*}$ in the HOMO -1 to LUMO +1 transition, which can be labeled as $L_{b 2}$, even though LUMO +1 shows a charge distribution that includes an interaction between the side chain and the closest molecules of water. In addition, the $S_{5}$ excited state, with a contribution of $78.07 \%$, shows a $\pi_{2} \rightarrow \pi_{2}^{*}$ transition, where label 2 refers to the first Trp of the cluster, which corresponds to the $L_{a 2}$ transition. Furthermore, the state $S_{8}$ with a significant oscillator strength parameter (0.0231) shows a transition from the first to the second Trp, which corresponds to $\pi_{1} \rightarrow \pi_{2}^{*}$, where the contribution occurs from the indole group in HOMO-3 to all the molecules of Trp in LUMO.

For the $(\operatorname{Trp})_{3}-\left(\mathrm{H}_{2} \mathrm{O}\right)_{27}$ and $(\operatorname{Trp})_{4}-\left(\mathrm{H}_{2} \mathrm{O}\right)_{36}$ clusters, more excited states were calculated based on the fact that every molecule of Trp in each cluster generates an electronic transition type $\pi \rightarrow \pi^{*}$ with a higher value of the oscillator strength parameter. This is the case for states $S_{1}, S_{2}$ and $S_{3}$ of the $(\operatorname{Trp})_{3}-\left(\mathrm{H}_{2} \mathrm{O}\right)_{27}$ cluster. However, Figure 8 shows the orbitals LUMO, LUMO + 1 and LUMO + 2 that provide a relatively smaller contribution from the neighboring molecules of Trp. It should be emphasized that upon increase in the cluster with a greater number of molecules of Trp, there are more interactions, mainly among the indole groups. For example, in the $(\operatorname{Trp})_{4}-\left(\mathrm{H}_{2} \mathrm{O}\right)_{36}$ cluster, the $S_{3}$ and $S_{5}$ states show transitions type $\pi \rightarrow \pi^{*}$, but these orbitals have a contribution shared from the indole group of Trp 3 and 4 . Transitions such as $S_{6}, S_{9}$ and $S_{17}$ were found to have contributions with the molecular orbitals, which correspond to only one of the molecules of Trp in the cluster. Likewise, as in the previous cases, the excited states such as $S_{22}$, which shows the contribution of molecules in absorption and their oscillator strength parameter, have a significant value (0.0511).

According to the discussion above, there are transitions where molecules of water and alanyl side chain interact, thus having a high probability of occurrence, which is a feature that should be taken into consideration. Therefore, in clusters with more than one molecule of Trp, excitation going from one molecule to a neighboring one occurs, such as in the $\mathrm{H}-3 \rightarrow \mathrm{L}$ transition at the $(\operatorname{Tr} p)_{2}$ $\left(\mathrm{H}_{2} \mathrm{O}\right)_{18}$ cluster. Moreover, in the case of the $(\operatorname{Trp})_{4}-\left(\mathrm{H}_{2} \mathrm{O}\right)_{36}$ cluster, the excited states where there are contributions in the molecular orbitals are observed, not only in one of the four molecules of Trp, but also in the participation of neighboring molecules of Trp (Figure 8).

Therefore, the solvent effect with a discrete model should include water molecules around the molecule of Trp, thereby allowing intramolecular interactions between the molecules of the solute and solvent to occur. Particularly, this is the case of solvents such as water, where some chemical reactions are present, thus leading to the stabilization of the zwitterionic forms.

\subsubsection{Fluorescence Emission Analysis}

The TD-DFT method was used at the B3LYP/6-31 + G(d,p) level to optimize the ground state (GS) and fluorescent state (FS) geometries only in the $(\operatorname{Trp})_{1}$ $\left(\mathrm{H}_{2} \mathrm{O}\right)_{9}$ cluster that has the $\mathrm{Zag}^{+}$and $\mathrm{Zpt}$ configurations. 
Figure 9 demonstrates the photoluminescent process of the $Z p t$ conformer. The cluster with its hydrogen bonds is excited to the state $S_{2}$ at a wavelength of $279.5 \mathrm{~nm}$. The states $S_{2}$ and $S_{1}$ are coupled and an internal conversion (IC) is generated by vibrational modes. After that, the system relaxes to its excited lowest point with an emission occurring at $348.9 \mathrm{~nm}$. Figure 9 also shows that the Trp geometries in the GS and FS are qualitatively similar, although some hydrogen bond lengths differ significantly. Actually, the bond length between the nitrogen atom of the aromatic ring and the oxygen atom of the nearest molecule of water decreases from 1.904 to $1.796 \AA$, and so do two zwitterion bonds from 1.842 to $1.766 \AA$ and 1.739 to $1.723 \AA$. The strong hydrogen bonds indicate that the pyrrole ring and the surrounding zwitterion are important to the fluorescent process of Trp in water.

In Figure 10, the computed FS for the $(\operatorname{Trp})_{1}-\left(\mathrm{H}_{2} \mathrm{O}\right)_{9}$ cluster that has the configurations $\mathrm{Zag}^{+}$and $\mathrm{Zpt}$ are comparable with those obtained for the experimental spectrum at any concentration, since the fluorescence peak located at 357 $\mathrm{nm}$ is in good agreement with the calculated fluorescence wavelength located at

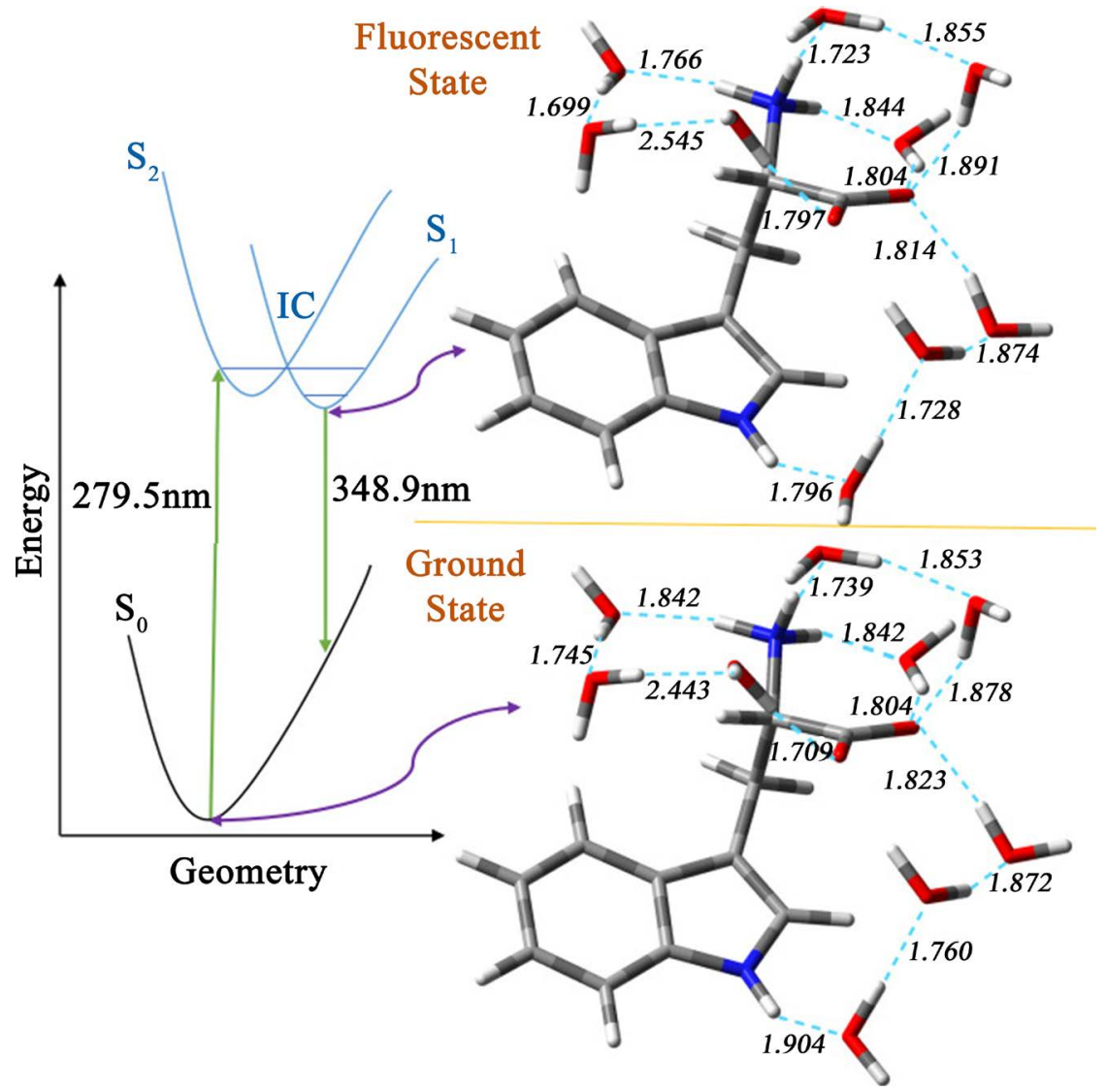

Figure 9. Representative diagram of the photoluminescent process for the $(\operatorname{Trp})_{1}-\left(\mathrm{H}_{2} \mathrm{O}\right)_{9}$ cluster with the $Z p t$ conformer. The absorption of the $S_{2}$ excited state and the emission of the $S_{1}$ excited state are shown here. The optimized geometrical structures of the GS and the FS $\left(S_{1}\right)$ have been included. The dashed blue lines show the representative hydrogen bond lengths measured in Angstrongs ( $\AA$ ) in the cluster for the GS and $S_{1}$ excited state geometries. 


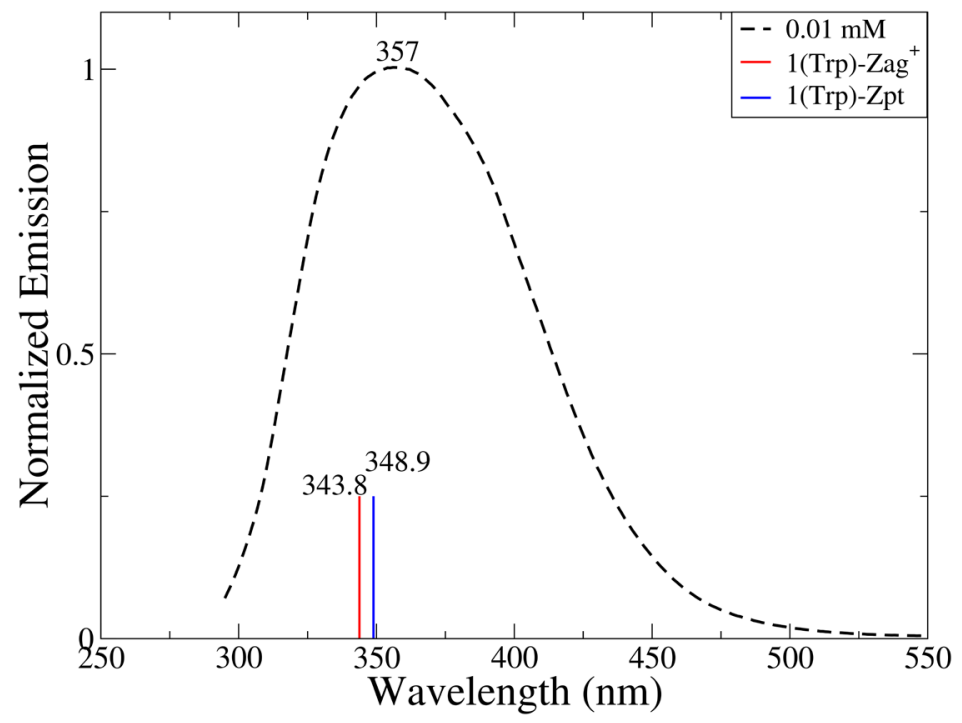

Figure 10. Experimental emission spectra of Trp in water, represented by the dashed black lines. The fluorescent states for the $(\operatorname{Trp})_{1}-\left(\mathrm{H}_{2} \mathrm{O}\right)_{9}$ cluster and for the $\mathrm{Zag} \mathrm{g}^{+}$and $\mathrm{Zpt}$ conformers are represented by the red and blue lines, respectively.

approximately $349 \mathrm{~nm}$ for the $Z p t$ structure. The fluorescent states for the $Z p t$ and $\mathrm{Zag}^{+}$conformers are very similar to the experimental value at 8 and $13 \mathrm{~nm}$, respectively. However, the $Z p t$ structure is more stable in water, which is closer to the experimental results.

The FS of the $(\operatorname{Trp})_{1}-\left(\mathrm{H}_{2} \mathrm{O}\right)_{9}$ cluster located at $349 \mathrm{~nm}$ corresponds to the orbital transition from HOMO to LUMO of type $\pi \rightarrow \pi^{*}$, based on the theoretical results of this work (Figure 8). It should be noted that in both orbitals the electron densities are located in the indole group.

\section{Conclusions}

In this work, the excitation redshift through the wavelength experimentally generated by increasing the concentration parameter of Trp in water has been investigated. At the considered concentrations, the excitation peak appears in the absorption band maxima, which indicates that the excitation is accomplished only at high concentrations with absorption toward lower energy states in the larger absorption band maxima.

By using the TD-DFT method, all spectral calculations for our clusters were found to be in good agreement with the experimental results in this work. The interactions among indole groups, side chains and molecules of water that lead to the redshift of spectral lines were studied at a molecular level. It was found that the contribution of molecules of water around Trp is non-negligible since hydrogen bonds stabilize the zwitterionic form.

Emission spectra were measured at the different concentrations, and the results were compared with the fluorescent states using the TD-DFT method for the first cluster. It was found that strong hydrogen bonds in the zwitterion and in the pyrrole ring play an important role in fluorescence. 
In general, the results indicate similar experimental and theoretical tendencies.

\section{Acknowledgements}

The authors gratefully acknowledge Laboratorio Nacional de Supercómputo del Sureste de México (LNS) at BUAP for the computational support and Consejo Nacional de Ciencia y Tecnología (CONACyT) for Scholarship No. 582282.

\section{Conflicts of Interest}

The authors declare no conflicts of interest regarding the publication of this paper.

\section{References}

[1] Callis, P.R. (1997) ${ }^{1} L_{a}$ and ${ }^{1} L_{b}$ Transitions of Tryptophan: Applications of Theory and Experimental Observations to Fluorescence of Proteins. Methods in Enzymology, 278, 113-150. https://doi.org/10.1016/S0076-6879(97)78009-1

[2] Daizadeh, I., Medvedev, E.S. and Stucherbrukhov, A.A. (1997) Effect of Protein Dynamics on Biological Electron Transfer. Proceedings of the National Academy of Sciences of the United States of America, 94, 3703-3708. https://doi.org/10.1073/pnas.94.8.3703

[3] Wetlaufer, D.B. (1963) Ultraviolet Spectra of Proteins and Amino Acids. Advances in Protein Chemistry, 17, 303-390. https://doi.org/10.1016/S0065-3233(08)60056-X

[4] Lacowicz, J.R. (2006) Principles of Fluorescence Spectroscopy. Springer, New York.

[5] Gryczynski, I., Wick, W., Johnson, M.L. and Lakowicz, J.R. (1998) Lifetime Distributions and Anisotropy Decays of Indole Fluorescence in Cyclohexane/Ethanol Mixtures by Frequency-Domain Fluorometry. Biophysical Chemistry, 32, 173-185. https://doi.org/10.1016/0301-4622(88)87005-4

[6] Snoek, L.C., Kroemer, R.T., Hockridge, M.R. and Simons, J.P. (2001) Conformational Landscapes of Aromatic Amino Acids in the Gas Phase: Infrared and Ultraviolet Ion Dip Spectroscopy of Tryptophan. Physical Chemistry Chemical Physics, 3, 1819-1826. https://doi.org/10.1039/b101296g

[7] Snoek, L.C., Kroemer, R.T. and Simons, J.P. (2002) A Spectroscopic and Computational Exploration of Tryptophan-Water Cluster Structures in the Gas Phase. Physical Chemistry Chemical Physics, 4, 2130-2139. https://doi.org/10.1039/b200059h

[8] Nolting, D., Marian, C. and Weinkauf, R. (2002) Protonation Effect on the Electronic Spectrum of Tryptophan in the Gas Phase. Physical Chemistry Chemical Physics, 6, 2633-2640. https://doi.org/10.1039/b316669d

[9] Gindensperger, E., Haegy, A., Daniel, C. and Marquardt, R. (2010) Ab Initio Study of the Electronic Singlet Excited-State Properties of Tryptophan in the Gas Phase: The Role of Alanyl Side-Chain Conformations. Chemical Physics, 374, 104-110. https://doi.org/10.1016/j.chemphys.2010.07.004

[10] Sobolewski, A.L., Shemesh, D. and Domcke, W. (2009) Computational Studies of the Photophysics of Neutral and Zwitterionic Amino Acids in an Aqueous Environment: Tyrosine- $\left(\mathrm{H}_{2} \mathrm{O}\right)_{2}$ and Tryptophan- $\left(\mathrm{H}_{2} \mathrm{O}\right)_{2}$ Clusters. The Journal of Physical Chemistry $A, 113,542-550$. https://doi.org/10.1021/jp8091754

[11] Hurtado, J.M., Menéndez, M.I., Lopez, R. and Lopez, M.F.R. (2014) An ab Initio Analysis of the Structure of L-Tryptophan Tautomers in Microhydrated Environments, in Water and in Hydrophobic Solvents. Computational and Theoretical Che- 
mistry, 1034, 17-25. https://doi.org/10.1016/j.comptc.2014.02.014

[12] Blom, M.N., Compagnon, I., Polfer, N.C., Helden, V.G., Meijer, G., Suhai, S., Paizd, B. and Oomens, J. (2007) Stepwise Solvation of an Amino Acid: The Appearance of Zwitterionic Structures. The Journal of Physical Chemistry A, 111, 7309-7316. https://doi.org/10.1021/jp070211r

[13] Liu, H., Zhang, H. and Jin, B. (2007) Fluorescence of Tryptophan in Aqueous Solution. Spectrochimica Acta Part A: Molecular and Biomolecular Spectroscopy, 106, 54-59. https://doi.org/10.1016/j.saa.2012.12.065

[14] Martinez, E.V. and Labbé, A.T. (2010) The Role of Water in the Proton Transfer Reaction Mechanism in Tryptophan. Journal of Computational Chemistry, 31, 2642-2649. https://doi.org/10.1002/jcc.21559

[15] Jensen, J.H. and Gordon, M.S. (1995) On the Number of Water Molecules Necessary to Stabilize the Glycine Zwitterion. Journal of the American Chemical Society, 117, 8159-8170. https://doi.org/10.1021/ja00136a013

[16] Ghassemizadeh, R., Moore, B., Momose, T. and Walter, M. (2019) Stability and IR Spectroscopy of Zwitterionic Form of $\beta$-Alanine in Water Clusters. The Journal of Physical Chemistry B, 123, 4392-4399. https://doi.org/10.1021/acs.jpcb.9b00654

[17] Leyton, P., Brunet, J., Silva, V., Paipa, C., Castillo, M.V. and Brandán, S A. (2012) An Experimental and Theoretical Study of L-Tryptophan in an Aqueous Solution, Combining Two-Layered ONIOM and SCRF Calculations. Spectrochimica Acta Part A: Molecular and Biomolecular Spectroscopy, 88, 162-170. https://doi.org/10.1016/j.saa.2011.12.023

[18] Huang, Z. and Lin, Z. (2005) Detailed Ab Initio Studies of the Conformers and Conformational Distributions of Gaseous Tryptophan. The Journal of Physical Chemistry A, 109, 2656-2659. https://doi.org/10.1021/jp0461201

[19] Compagnon, I., Hagemeister, F.C., Antoine, R., Rayane, D., Broyer, M., Dugourd, P., Hudgins, R.R. and Jarrold, M.F. (2001) Permanent Electric Dipole and Conformation of Unsolvated Tryptophan. Journal of the American Chemical Society, 123, 8440-8441. https://doi.org/10.1021/ja010965y

[20] Dezube, B., Dobson, C.M. and Teague, C.E. (1981) Conformational Analysis of Tryptophan in Solution using Nuclear Magnetic Resonance Methods. Journal of the Chemical Society, Perkin Transactions 2, 4, 730-735. https://doi.org/10.1039/p29810000730

[21] Eriksen, J.J., Olsen, J.M.H., Aidas, K., Agren, H., Mikkelsen, K.V. and Kongsted, J. (2011) Computational Protocols for Prediction of Solute NMR Relative Chemical Shifts. A Case Study of L-Tryptophan in Aqueous Solution. Journal of Computational Chemistry, 32, 2853-2864. https://doi.org/10.1002/jcc.21867

[22] Mark, P. and Nilsson, L. (2002) A Molecular Dynamic Study of Tryptophan in Water. The Journal of Physical Chemistry B, 106, 9440-9445. https://doi.org/10.1021/jp025965e

[23] Platt, J.R. (1949) Classification of Spectra of Cata-Condensed Hydrocarbons. The Journal of Chemical Physics, 17, 484-495. https://doi.org/10.1063/1.1747293

[24] Yamamoto, Y. and Tanaka, J. (1972) Polarized Absorption Spectra of Crystals of Indole and Its Related Compounds. Bulletin of the Chemical Society of Japan, 45, 1362-1366. https://doi.org/10.1246/bcsj.45.1362

[25] Valeur, B. and Weber, G. (1977) Resolution of the Fluorescence Excitation Spectrum of Indole into the ${ }^{1} \mathrm{~L}_{\mathrm{a}}$, and ${ }^{1} \mathrm{~L}_{\mathrm{b}}$ Excitation Bands. Photochemistry and Photobiology, 25, 441-444. https://doi.org/10.1111/j.1751-1097.1977.tb09168.x 
[26] Teale, F.W.J. and Weber, G. (1957) Ultraviolet Fluorescence of the Aromatic Amino Acids. Biochemical Journal, 65, 476-482. https://doi.org/10.1042/bj0650476

[27] Weber, G. (1960) Fluorescence-Polarization Spectrum and Electronic-Energy Transfer in Tyrosine, Tryptophan and Related Compounds. Biochemical Journal, 75, 335-345. https://doi.org/10.1042/bj0750335

[28] Sun, M. and Song, P.-S. (1977) Solvent Effects on the Fluorescent States of Indole Derivatives-Dipole Moments. Photochemistry and Photobiology, 25, 3-9. https://doi.org/10.1111/j.1751-1097.1977.tb07416.x

[29] Tatisheff, L., Klein, R., Zemb, T. and Duquesne, M. (1978) Solvent Interactions with the Indole Chromophore. Chemical Physics Letters, 54, 394-398. https://doi.org/10.1016/0009-2614(78)80127-4

[30] Eftink, M.R., Selvidge, L.A., Callis, P.R. and Rehms, A.A. (1990) Photophysics of Indole Derivatives: Experimental Resolution of $L_{a}$ and $L_{b}$ Transitions and Comparison with Theory. The Journal of Physical Chemistry, 94, 3469-3479. https://doi.org/10.1021/j100372a022

[31] Markley, J.L., Bax, A., Arata, Y., Hilbers, C.W., Kaptein, R., Sykes, B.D., Wright, P.E and Wuthrich, K. (1990) Recommendations for the Presentation of NMR Structures of Proteins and Nucleic Acids. Journal of Molecular Biology, 280, 933-952. https://doi.org/10.1006/jmbi.1998.1852

[32] Lewars, E.G. (2003) Computational Chemistry: Introduction to the Theory and Applications of Molecular and Quantum Mechanics. Springer, Peterborough.

[33] Engler, E.M., Andose, J.D. and Schleyer, P.V.R. (1973) Critical Evaluation of Molecular Mechanics. Journal of the American Chemical Society, 95, 8005-8025. https://doi.org/10.1021/ja00805a012

[34] Formosinho, S.J., Csizmadia, I.G. and Arnaut, L.G. (1991) Theoretical and Computational Models for Organic Chemistry. Springer, Dordrecht.

https://doi.org/10.1007/978-94-011-3584-9

[35] Mayo, S.L., Olafson, B.D. and Goddard III, W.A. (1990) DREIDING: A Generic Force Field for Molecular Simulations. The Journal of Physical Chemistry, 94, 88978909. https://doi.org/10.1021/j100389a010

[36] Stewart, J.J.P. (2007) Optimization of Parameters for Semiempirical Methods V: Modification of NDDO Approximations and Application to 70 Elements. Journal of Molecular Modeling, 13, 1173-1213. https://doi.org/10.1007/s00894-007-0233-4

[37] Bauernschmitt, R. and Ahlrichs, R. (1996) Treatment of Electronic Excitations within the Adiabatic Approximation of Time Dependent Density Functional Theory. Chemical Physics Letters, 256, 454-464. https://doi.org/10.1016/0009-2614(96)00440-X

[38] Stratmann, R.E. and Scuseria, G.E. (1998) An Efficient Implementation of TimeDependent Density-Functional Theory for the Calculation of Excitation Energies of Large Molecules. The Journal of Chemical Physics, 109, 8218-8224. https://doi.org/10.1063/1.477483

[39] Van Caillie, C. and Amos, R.D. (1999) Geometric Derivatives of Excitation Energies Using SCF and DFT. Chemical Physics Letters, 308, 249-255. https://doi.org/10.1016/S0009-2614(99)00646-6

[40] Van Caillie, C. and Amos, R.D. (2000) Geometric Derivatives of Density Functional Theory Excitation Energies Using Gradient-Corrected Functionals. Chemical Physics Letters, 317, 159-164. https://doi.org/10.1016/S0009-2614(99)01346-9

[41] Furche, F. and Ahlrichs, R. (2002) Adiabatic Time-Dependent Density Functional 
Methods for Excited State Properties. The Journal of Chemical Physics, 117, 7433 7447. https://doi.org/10.1063/1.1508368

[42] Scalmani, G., Frisch, M.J., Mennucci, B., Tomasi, J., Cammi, R. and Barone, V. (2006) Geometries and Properties of Excited States in the Gas Phase and in Solution: Theory and Application of a Time-Dependent Density Functional Theory Polarizable Continuum Model. The Journal of Chemical Physics, 124, 094107. https://doi.org/10.1063/1.2173258

[43] Adamo, C. and Jacquemin, D. (2013) The Calculations of Excited-State Properties with Time-Dependent Density Functional Theory. Chemical Society Reviews, 42, 845-856. https://doi.org/10.1039/C2CS35394F

[44] Laurent, A.D., Adamo, C. and Jacquemin, D. (2014) Dye Chemistry with TimeDependent Density Functional Theory. Physical Chemistry Chemical Physics, 16, 14334-14356. https://doi.org/10.1039/C3CP55336A

[45] Becke, A.D. (1993) Density-Functional Thermochemistry. III. The Role of Exact Exchange. The Journal of Chemical Physics, 98, 5648-5652.

https://doi.org/10.1063/1.464913

[46] Wachters, A.J.H. (1970) Gaussian Basis Set for Molecular Wave Functions Containing Third Row Atoms. The Journal of Chemical Physics, 52, 1033-1036. https://doi.org/10.1063/1.1673095

[47] Hay, P.J. (1977) Gaussian Basis Sets for Molecular Calculations. The Representation of 3d Orbitals in Transitionmetal Atoms. The Journal of Chemical Physics, 66, 4377-4384. https://doi.org/10.1063/1.433731

[48] Ditchfield, R., Hehre, W.J. and Pople, J.A. (1971) Self-Consistent Molecular Orbital Methods. 9. An Extended Gaussian-Type Basis for Molecular-Orbital Studies of Organic Molecules. The Journal of Chemical Physics, 54, 724-728. https://doi.org/10.1063/1.1674902

[49] Hariharan, P.C. and Pople, J.A. (1973) Influence of Polarization Functions on Molecular-Orbital Hydrogenation Energies. Theoretica Chimica Acta, 28, 213-222. https://doi.org/10.1007/BF00533485

[50] Rassolov, V.A., Ratner, M.A., Pople, J.A., Redfern, P.C. and Curtiss, L.A. (2001) 6-31G* Basis Set for Third-Row Atoms. Journal of Computational Chemistry, 22, 976-984. https://doi.org/10.1002/jcc.1058

[51] Frisch, M.J., Trucks, G.W., Schlegel, H.B., Scuseria, G.E., Robb, M.A., Cheeseman, J.R., Scalmani, G., Barone, V., Petersson, G.A., Nakatsuji, H., Li, X., Caricato, M., Marenich, A.V., Bloino, J., Janesko, B.G., Gomperts, R., Mennucci, B., Hratchian, H. P., Ortiz, J.V., Izmaylov, A.F., Sonnenberg, J.L., Williams-Young, D., Ding, F., Lipparini, F., Egidi, F., Goings, J., Peng, B., Petrone, A., Henderson, T., Ranasinghe, D., Zakrzewski, V.G., Gao, J., Rega, N., Zheng, G.,Liang, W., Hada, M., Ehara, M., Toyota, K., Fukuda, R., Hasegawa, J., Ishida, M., Nakajima, T., Honda, Y., Kitao, O., Nakai, H., Vreven, T., Throssell, K., Montgomery Jr., J.A., Peralta, J.E., Ogliaro, F., Bearpark, M.J., Heyd, J.J., Brothers, E.N., Kudin, K.N., Staroverov, V.N., Keith, T.A., Kobayashi, R., Normand, J.; Raghavachari, K., Rendell, A.P., Burant, J.C., Iyengar, S.S., Tomasi, J., Cossi, M., Millam, J.M., Klene, M., Adamo, C., Cammi, R., Ochterski, J.W., Martin, R. L., Morokuma, K., Farkas, O., Foresman, J.B. and Fox, D.J. (2016) Gaussian 16, Revision C.01. Gaussian, Inc., Wallingford. 